\title{
Broad ligament term pregnancy in an unscarred uterus: misdiagnosis and the challenges
}

\author{
Shalini Singh*, Madhubala Chauhan
}

\begin{abstract}
Department of Obstetrics and Gynecology, Panna Dhai Zannana Hospital, Rabindranath Tagore Medical College,
\end{abstract} Court Chowk, City's Prime Health Care Area, Udaipur, Rajasthan, India

Received: 29 May 2019

Accepted: 09 July 2019

*Correspondence:

Dr. Shalini Singh,

E-mail: shalini7679@gmail.com

Copyright: (c) the author(s), publisher and licensee Medip Academy. This is an open-access article distributed under the terms of the Creative Commons Attribution Non-Commercial License, which permits unrestricted non-commercial use, distribution, and reproduction in any medium, provided the original work is properly cited.

\begin{abstract}
A broad ligament pregnancy is a rare condition, but full term broad ligamnet pregnancy especially in an unscarred uterus is extremely rare. It is often misdiagnosed and usually finally diagnosed during surgery. Here is case of full term broad ligament pregnancy, which remained undiagnosed throughout her pregnancy, unfortunately had IUFD. Patient was referred to our hospital in view of failure of induction with increased BP records. No ultrasound was available on admission. On clinical assessment it appeared as transverse lie with IUFD. So cesarean was decided as a mode of delivery. Emergency ultrasound could just confirm IUFD with pelvic mass? Fibroid (actually deviated uterus). On laparotomy the broad ligament pseudosac had occupied entire abdomen. After delivery of baby, anatomy was found completely distorted. Highly vascular omental adhesions on fundus with difficulty in placental removal. Placenta could be traced reaching abdomen posteriorly. The first clinical impression was suspicion of placenta percreta. Uterus appeared non salvageable and hysterectomy was decided. Placenta was found lying in abdomen, adhered to bowel, omentum and fundus of uterus. The final diagnosis of broad ligament pregnancy could be made after the cut section of the uterus and anatomic evaluation. Patient required blood transfusions preoperatively. She remained stable and discharged on postoperative day nine. This case holds importance because may be outcome was different if it was a booked and investigated pregnancy. May be baby and uterus were salvageable with better outcome.
\end{abstract}

Keywords: Broad ligament pregnancy, Ectopic pregnancy, Obstetrical hemorrhage, Placenta insitu, Placenta percreta, Peripartum hysterectomy

\section{INTRODUCTION}

Broad ligament pregnancy is also called intra ligamentous pregnancy. It is a rare type of ectopic pregnancy. Its incidence is reported as 1 in 300 ectopic pregnancies. ${ }^{1}$ A broad ligament pregnancy can result due to secondary implantation of trophoblastic tissue from tubal ectopic pregnancy into the leaves of broad ligament or through a previous scar or uterine fistula. In literature few cases of term and early broad ligament pregnancies have been reported and even with term live babies. ${ }^{1-4,6}$ We report a case of an uninvestigated term pregnancy in an unscarred uterus, that was accidently found as broad ligament pregnancy after laparotomy.

We share the challenges faced by us to manage this rare case. We consider that outcome could have been different if it was a booked and investigated pregnancy or had patient reported earlier. May be misdiagnosis had been avoided with better outcomes and decisions. 


\section{CASE REPORT}

This patient was unbooked unsupervised and uninvestigated 32-year female, G2 P1 L1 at 38 weeks of gestation. Her previous vaginal delivery was 12 years back at home. She had history of primary infertility of 4 years followed by secondary infertility of 12 years. As told by patient both pregnancies were spontaneous conception. She did not give any history of medication or intervention for infertility treatment (which we found suspicious). Both of these pregnancies were unbooked and uninvestigated. She visited to local peripheral hospital with complain of absent fetal movement for 3 days, where she was diagnosed with IUFD. She was referred on next day to our hospital for failure of induction and increased B.P. records. She had no antenatal visits, and no ultrasound was available at the time of admission. On clinical assessment patient was stable, her B.P was 130/80 and no pallor clinically.

The uterus was term size, lower pole was empty, and head could be felt on right side while a prominent mass was palpable on left side of lower abdomen. The fetal heart sound was absent. The first clinical impression was? Transverse lie. On per vaginal examination, the cervix was found uneffaced, os closed, laterally displaced to right side and flushed up.

\section{Investigations}

Her urgent haemoglobin was $9.3 \mathrm{~g} \%$. The emergency ultrasonography could be done which confirmed IUFD with some pelvis mass on left side (actually uterus that could not be well differentiated ) with fetal head on right side. Decision for surgery was taken as per clinical diagnosis of IUFD with? Transverse lie may be due to pelvic mass. The diagnosis of broad ligament pregnancy was still missed, may be due to full term pregnancy and distorted anantomy.

\section{Surgery}

On opening the abdomen by modified phannenstiel incision, an 18 week size uterus appeared on left inferolateral side which falsely appeared as a fibroid occupying the lower segment. The broad ligament on right side formed a pseudo sac occupying whole anterior abdomen. The anatomy was distorted and uterus was indistinguishable from the broad ligament sac (Figure 1), round ligament was seen on left side but could not be traced on right side. ( $\mathrm{J}$ shaped incision was given on lower segment of the sac, considering the falsely appearing fibroid (actually uterus) occupying incision line. A macerated IUFD, female fetus of $2.7 \mathrm{~kg}$ was delivered with vertex presentation and meconium stained liquor. Placenta was tried to be delivered by control cord traction but could not be delivered which gave suspicion of adhered placenta. The uterus was exteriorized and highly vascular dense omental adhesions were encountered on fundus (Figure 2).

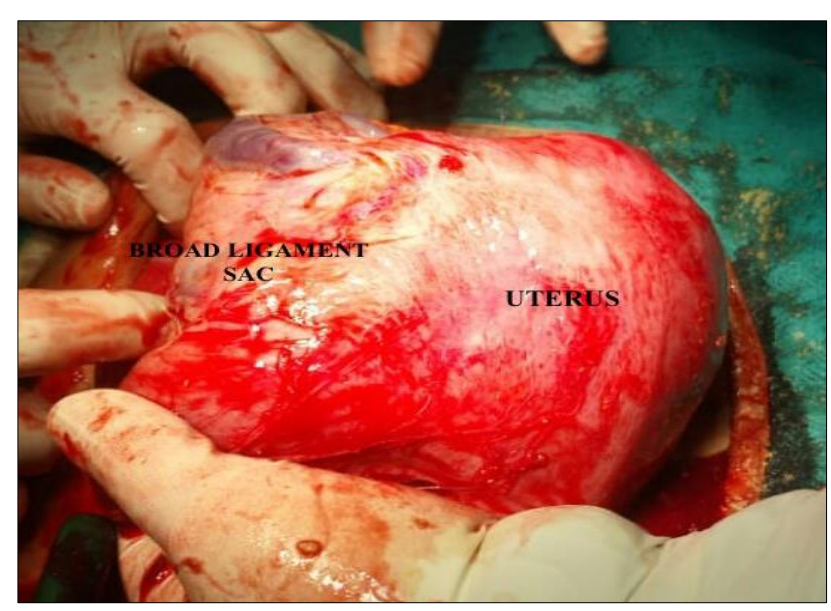

Figure 1: After delivery of baby by incision on pseudo sac occupying whole abdomen, on exteriorization showed uterus with broad ligament sac as whole giving impression of uterus externally. Uterus (left) seen deviated (which initially gave false impression of fibroid on lower segment on opening the abdomen). Broad ligament pseudo sac (right), both of them could not be differentiate and gave false impression of intrauterine pregnancy with vascularity on fundus.

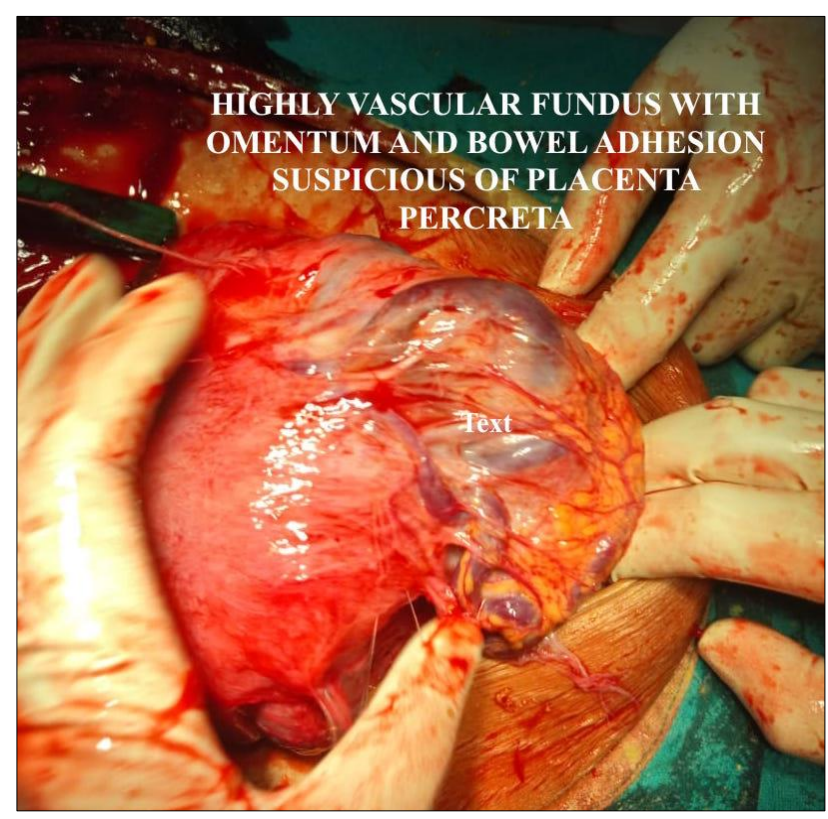

Figure 2: High vacularity on fundus with omental adhesion on fundus and bowel posteriorly, placenta could be traced posterior to uterus giving false impression of placenta percreta.

The placental bed appeared thinned out posteriorly which was actually formed by posterior leaflet of broad ligament, with adhesion to bowel loops. It gave suspicion of placenta percreta (Figure 3). The uterus appeared not salvageable, hence decision for subtotal hysterectomy was taken (Figure 4) after adhesiolysis from omentum and bowel. Following this the intact placenta was found lying in abdomen which had perforated through posterior 
leaflet of broad ligament (Figure 5). The cut section of specimen showed intact uterus (Figure 6). Final evaluation of anatomy suggested as broad ligament pregnancy. A drain was placed. And two units of packed red blood cells were transfused per operatively.

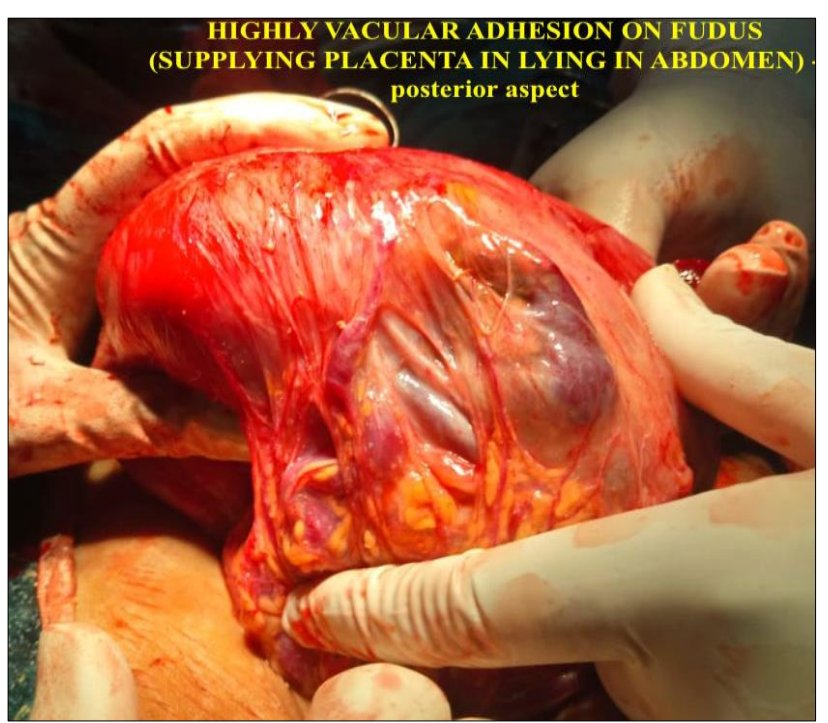

Figure 3: Posterior view of uterus showing adhesions and vasularity, feeding vessels to placenta lying in abdomen giving impression of placenat percreta hence Uterus appeared non salvagable and hysterectomy was decided.

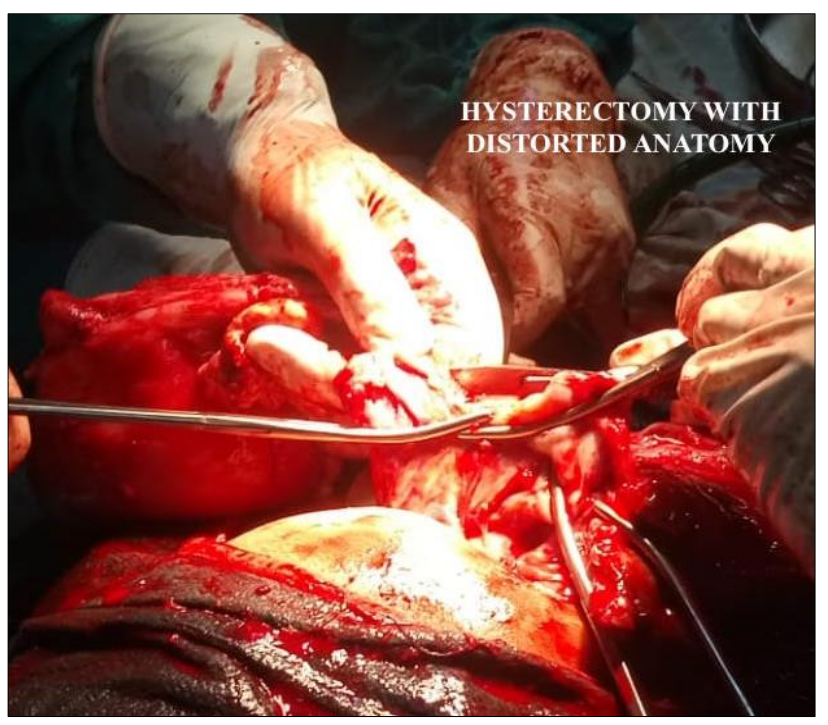

Figure 4: The amount of blood loss and hysterectomy with distorted antomy in view of placenta per creta.

\section{Outcome and follow-up}

Postoperatively the patient was managed with one unit blood transfusion and routine medication. Patient remained stable except for $150 \mathrm{ml}$ serous discharge that continued in drain till seventh post op day period and associated hypoalbuminemia. She was discharged on post op day nine in healthy condition.

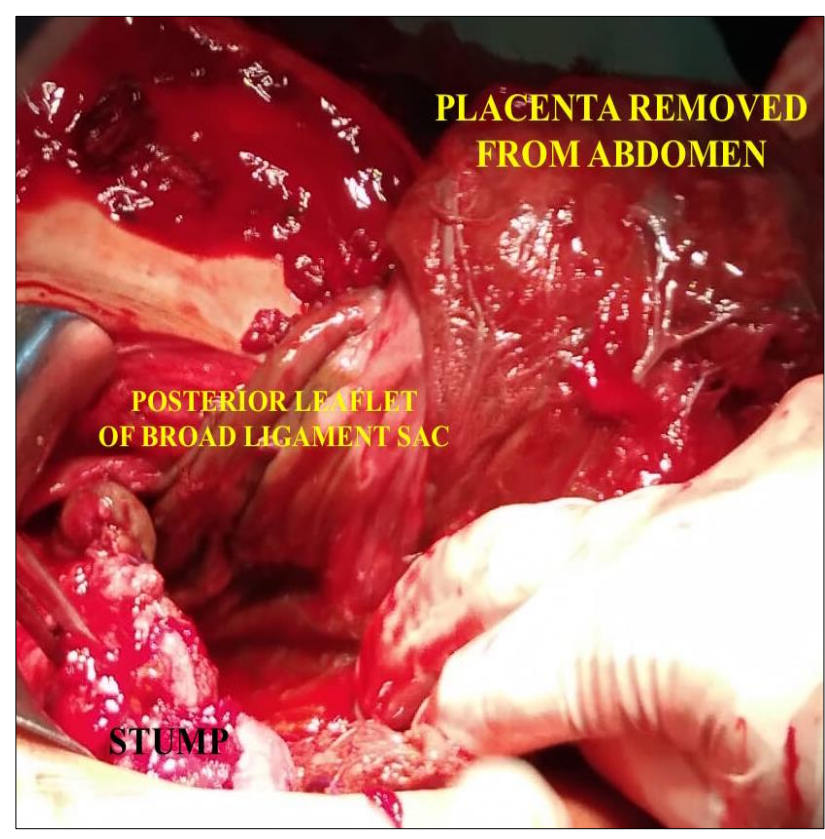

Figure 5: Post subtotal hysterectomy showing stump. Placenta being removed from abdomen, reaching through and posterior leaflet of broad ligament.

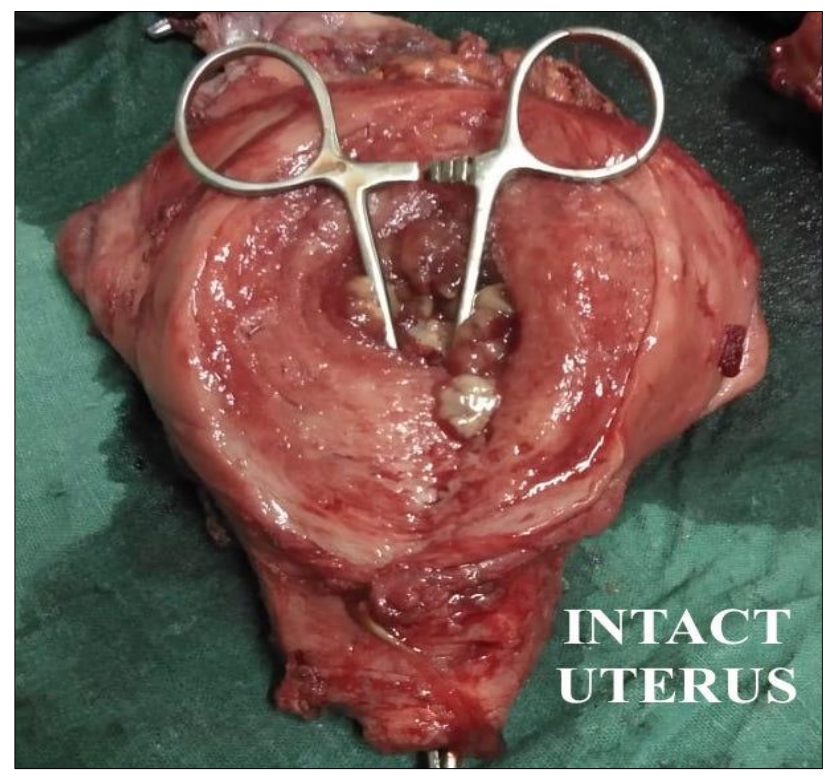

Figure 6: The cut section showed intact walls of uterus. Hence anatomical evaluation let us diagnose broad ligament pregnancy.

\section{Differential diagnosis: diagnostic dilemma}

\section{Preoperative diagnosis}

On clinical assessment transverse lie with IUFD was our preoperative diagnosis. As there was failure of induction from referred hospital, secondly the uterus that occupied 
the left side of abdomen with fetal head on right side gave impression of transverse lie with empty lower pole.

\section{Preoperative first diagnosis}

Placenta percreta was the first impression during laprotomy. We encountered dense adhesion of omentum on fundus and posteriorly on uterus. Uterus could not be differentiated from broad ligament pseudo sac that occupied the whole anterior abdomen until hysterectomy was performed.

\section{Final diagnosis}

Broad ligament pregnancy was made once adhesiolysis was done follwed by hysterctomy with distorted anatomy. Placenta had invaded posterior leaflet of broad ligament, it was lying in abdomen. The cut section of uterus showed all intact walls without any evidence of communication with broad ligament or with placenta.

\section{Outcome and follow-up}

Patient stood the surgery well, except the amount of blood loss that required blood transfusions. Patient was discharged on ninth post op day period with stable condition and hemoglobin of $10 \mathrm{mg} / \mathrm{dl}$.

\section{DISCUSSION}

Broad ligament pregnancy is a rare and a life threatening condition. It has been reported to be associated with high maternal mortality up to $20 \%$, perinatal mortality ranging between 40 and $90 \%$ and fetal deformities up to $21.4 \% .^{5}$

It can be primary broad ligament pregnancy due to implantation of the zygote on the broad ligament or secondary from implantation in fallopian tube, ovary or other peritoneal surface. Usually it results from trophoblastic penetration of tubal pregnancy through the tubal serosa and into the mesosalpinx, with secondary implantation between the leaves of broad ligament. It can also occur if a uterine fistula develops between the endometrial cavity and the retroperitoneal space between the leaves of broad ligament. Rarely it can occur through caesarean scar, or after uterine perforation, and after hysterectomy. ${ }^{6}$ In present case uterus and tubes were found intact without any evidence of fistulous tract. broad ligament had transformed into pseudosac with placenta perforated through its posterior leaflet and lying in abdomen.

In such cases early diagnosis is essential and critical, to avoid the catastrophic complication at any stage. When the patient does not present with clinical symptoms, a thorough obstetrics assessment including abdominal palpation and per vaginal examination may raise a clinical suspicion. Failure of induction with high presentation should also give high suspicion of extrauterine pregnancy. An ultrasound is an effective method for diagnosis but MRI is more accurate. Surgical intervention is recommended as soon as an abdominal pregnancy is diagnosed. The diagnosis of the full term broad ligament pregnancy is difficult and usually misdiagnosed. The final diagnosis is often made during a laparotomy as in our case.

In our case only emergency sonographic evaluation could be done (difficult to diagnose due to term pregnancy). Per op the anatomy was so distorted that the first clinical impression was suspicion of placenta percreta. Uterus appeared non salvageable and hysterectomy was decided. The final diagnosis of broad ligament pregnancy could be made after the cut section of the uterus and evaluation. In this case baby was IUFD with meconium stained liquor but had no skeletal anomalies. The management is still debatable especially related to placenta. The challenges in such cases are whether we should proceed for hysterectomy with high risk of uncontrollable hemorrhage. Or alternative of uterus sparing method and leaving the placenta insitu for autolysis (LISA) and follow up or use of methotrecxate. ${ }^{7-9}$

In this case had this patient been investigated and had a planned delivery, maybe we could have proceeded with alternative method and may be her uterus and baby were salvageable. Every case is a new case and different, hence proper evaluation of anatomy is mandatory. Such cases need management at tertiary level with adequate resuscitative measures, blood products and ICU facilities. Early diagnosis and referral can be life saving.

\section{Learning points/take home messages}

- India is still a developing country, we are taking many measures and have many programmes to reduce maternal mortality and still birth,yet there is lack of a proper maternal evaluation, assessment and early referral and facilities at periphery level

- Infertility is a growing problem now days. Poor socioeconomic people, illiteracy, lack of knowledge compel them for abnormal methods and believes which patients hide or don't care to share with their doctors

- Many patients don't understand the importance and necessity of proper antenatal visits, checkup and institutional delivery

- In this case, the patient wasn't booked for antenatal checkups, hence could not be investigated and diagnosed. She had history of 12 years of secondary infertility, but still refuses to give any history of treatment or intervention. She had complains of decreased fetal movement for 3 days, still didn't reported to hospital

- If she was a booked patient and properly evaluated, we could have avoided IUFD, misdiagnosis and hysterectomy (if possible). We may have chosen the alternative measure to avoid massive hemmorages and risk the life, placenta could be left in-situ for autolysis and followed up. 


\section{Patient's perspective}

Patient agreed that she failed to visit the hospital during her pregnancy as her previous delivery was at home. She also failed to report to hospital when she failed to perceive fetal movements for past three days. But she was happy that her life was saved with grief of the loss of her baby.

\section{ACKNOWLEDGEMENT}

Authors would like to thank, Head of the department Prof. Madhubala Chauhan, for her guidance and support. Thanks to junior residents for helping me in follow-up and care of patient. Thanks to the patient and her family for being so cooperative throughout and hence helping us in our learning curriculum.

\section{Funding: No funding sources}

Conflict of interest: None declared

Ethical approval: Not required

\section{REFERENCES}

1. Vierhout ME, Wallenburg HC. Intraligamentary pregnancy resulting in a live infant. Am J Obstet Gynecol. 1985;152:878-9.

2. Sheela CN, Mhaskar A, Karanth S. Advanced intraliga-mentary pregnancy resulting in a live birth. J Obstet Gynecol India. 2011;57:548-9.

3. Singh U, Singh N, Sankhwar P. Full-term viable broad ligament pregnancy surgically managed with favor- able feto-maternal outcome. J Obstet Gynecol India. 2012;62:23-4.

4. Akhtar N. Ectopic pregnancy and full term live birth: a case report. J Postgrad Med Inst. 2011;25:181-2.

5. Baffoe P, Fofie C, Gandau BN. Term abdominal pregnancy with healthy new born: a case report. Ghana Med J. 2011;46(2):81-3.

6. Rudra S. Full term broad ligament pregnancy through a Cesarean scar. Case Report Obstet Gynecol Sci. 2013;56(6):404-7.

7. Gupta A. Save the uterus, J Fetal Med. 2014;1(4):181-5.

8. Boekhoff J. Leaving the placenta in situ approach (LISA) in a patient with placenta increta leading to delayed spontaneous delivery of the placenta. J Maternal-Fetal Neonatal Med. 2018. Available at: https://www.tandfonline.com/doi/abs/10.1080/14767 058.2018.1488960.

9. Oriaifo N. Adjunctive use of methotrexate in the management of advanced abdominal pregnancy: a case report and literature review. Int Res J Pharmacy Pharmacol. 2014;4(2):18-21. Available at: https://pdfs.semanticscholar.org/07c9/2703a295c9c5f 787a2be6c136f9bfeaee51a.pdf.

Cite this article as: Singh S, Chauhan M. Broad ligament term pregnancy in an unscarred uterus: misdiagnosis and the challenges. Int J Reprod Contracept Obstet Gynecol 2019;8:3377-81. 